\title{
Federal Mandates by Popular Demand
}

\author{
Jacques Crémer \\ Centre National de la Recherche Scientifique and Institut d'Economie Industrielle, Université de \\ Toulouse
}

\section{Thomas R. Palfrey}

California Institute of Technology

\begin{abstract}
This paper proposes a new framework for studying federal mandates regarding public policies in areas such as environmental quality, public health, highway safety, and the provision of local public goods. Voters have single-peaked preferences along a single policy dimension. There are two levels of government, federal and local. The federal level can constrain local policy by mandating a minimum (or maximum) policy. Localities are free to adopt any policy satisfying the constraint imposed by the federal mandate. We show that voters choose federal mandates that are too strict, which leads to excessively severe mandates. We show that similar results can obtain when federal provision of the publicprovided good is more efficient than local provision.
\end{abstract}

\section{Introduction}

Many policies are determined through a combination of decisions at various levels of government. Policy makers at a higher level of government specify guidelines that must be satisfied by policies decided at lower levels. For example, the Environmental Protection Agency establishes emissions standards for gasoline-powered vehicles, which may then

We wish to thank Laboratoire Commun de Recherche en Économie de l'Environnement, de l'Énergie et du Secteur Public for financial support. Useful comments were provided by Jenna Bednar, Jean Tirole, a referee, and the editor, as well as seminar participants at Virginia Polytechnic Institute, Toulouse, Munich, Lisbon, the 1998 meeting of the Public Choice Society, and the 1998 Wallis Conference in Political Economy.

[Journal of Political Economy, 2000, vol. 108, no. 5]

(C) 2000 by The University of Chicago. All rights reserved. 0022-3808/2000/10805-0002\$02.50 
be strengthened (but not relaxed) by each state. Other examples include educational curriculum and service requirements and highway and workplace safety standards. Some kinds of government expenditures also follow this pattern: for example, the federal government provides basic welfare support to poor families with children, which is often supplemented by state welfare grants; federal income taxes are determined by Congress, and additional income taxes can be imposed by states and municipalities. The same pattern can be found in the European Union, where, for instance, the European Court of Justice imposes minimum standards of respect for certain human rights or the European Commission imposes a minimum amount of competition in network industries.

Observers often complain that the constraints imposed by central levels of government on local levels are too strict. More precisely, there are circumstances in which central governments intervene even when interjurisdictional externalities are minimal, in which case such intervention is difficult to explain in terms of efficiency gains. Consider, for instance, the fact that grants given by the U.S. government to states for maintenance of highways are reduced if they do not raise the drinking age to 21 , or the fact that U.S. regulations require local governments to move city fuel tanks above ground (Peterson 1995). Following the lead of the public choice school, most economists and political scientists would, we surmise, interpret this excessive intervention by central governments as the consequence of power grabbing by politicians.

The main message of this paper is that such excessive interference has deeper roots. It is a "normal" consequence of the behavior of voters and a probably unavoidable feature of federal systems. Local political fights have a tendency to spill over at the federal level, as voters will try to have their preferred policy imposed at both levels of government. Recent political debates in the European Union provide many examples: the staunchest defenders of "subsidiarity" on some issues become ardent advocates of European intervention on others. A report to the French Senate (La Malène 1996/97) gives striking examples. For instance, through a resolution of November 18, 1992, the European Parliament has expressed its support to the principle of subsidiarity. This did not prevent its Environmental Commission from complaining when a text on the reduction of water pollution by water mills was withdrawn from the agenda.

In order to study mandates, we examine the equilibrium of a hierarchical pattern of policy making in which, at each level, decisions are

\footnotetext{
${ }^{1}$ Subsidiarity is a general principle of European law, which states that, except in the areas in which it has exclusive competence, the European Community intervenes only as far as the objectives of the policy that is considered cannot be reached by the member states.
} 
made by majority vote. We identify the equilibrium effects of multiple layers of government and compare the outcomes under the hierarchical system of mandates to the outcomes that arise if policies are determined either exclusively at the federal level or exclusively at the local level.

Our model is based on the standard one-dimensional spatial model, in which voters have single-peaked preferences and political competition produces median voter outcomes. Policies at both the federal and state levels are determined according to majority rule equilibrium. The federal mandate is set in the first stage, and it becomes a lower bound to the policy choice of each district in the second stage.

We first consider a baseline case, without externalities or other possible sources of efficiency gains from federal intervention. We find that voters will vote sincerely at each stage, and therefore there will be stricter standards with the hierarchical structure than with a system in which policy is determined entirely at the local level. Furthermore, there will be less variance of policy outcomes across local jurisdictions. More voters are made worse off than better off, compared to a world without federal mandates.

We then extend the model to allow for efficiency gains from federal intervention. We do this by modeling the local public good outcome as the sum of a level provided by the federal government (similar to a mandate) plus whatever additional amount the district chooses to produce locally. Local production of the public good is assumed to be less efficient than production by the federal government because of economies of scale (or scope) or greater efficiency of federal taxation. Even with significant efficiency gains from federal provision, majority voting can still lead to a higher level of provision than would be optimal under a utilitarian welfare criterion. Finally, we show that, surprisingly, the level of federal expenditures will be higher the more efficient the local governments are at providing public goods.

While our framework is, as far as we know, entirely new to the literature, a number of papers touch on related issues. Bednar (1998) and de Figueiredo and Weingast (1997) investigate and discuss the impacts of and pressures leading to federal encroachment of the kind that has preoccupied constitutional scholars and designers for centuries. In the public finance literature, Nechyba $(1997 a, 1997 b)$ has studied equilibrium properties of financing locally public projects through a combination of income taxes (which normally occur at state or national levels) and property taxes (which normally are imposed by local authorities). There is also a vast literature in the field of regulation that addresses the specific effects of federal standards in a variety of applied settings including product safety, air and water quality, public health standards, and other policy domains. However, none of this formally models the 
interaction of federal regulatory agencies and regulatory authorities at lower levels of government. ${ }^{2}$

The theory presented in this paper is mostly positive, but it should inform normative theories, as illustrated by the comparison of the efficiency regimes of different federalist regimes of Section IV. We discuss this link, as well as the relationship to a broader research program, in Section V.

The remainder of the paper is organized in the following way. Section II presents the basic model and results. Section III explores the extension to allow for efficiency gains from federal provision. Section IV presents an extended parametric example that illustrates the welfare properties of the equilibrium. Section V discusses directions for further research.

\section{The Basic Model}

We consider a confederation composed of $D$ districts, where $D$ is an odd integer equal to at least three. Each district has an odd number of voters.

Voters have complete and transitive preferences over the policy space $\Re^{+}$; the preferences of voter $(i, d)$-that is, voter $i$ in district $d$-are represented by the utility function $U_{d}^{i}\left(x_{d}\right)$, where $x_{d} \in \mathfrak{R}^{+}$is the policy outcome in district $d$, and $t_{i d}=\arg \max _{x} U_{d}^{i}(x)$ is his or her ideal policy. These preferences are single-peaked: $U_{d}^{i}$ is strictly increasing on $(-\infty$, $\left.t_{i d}\right]$ and strictly decreasing on $\left[t_{i d},+\infty\right)$.

The median ideal policy in district $d$ is $m_{d}=\operatorname{med}_{(i, d)}\left\{t_{i d}\right\}$. The median ideal policy for all voters in all districts will be called $M$. To simplify the exposition we assume that no two voters have the same ideal policy. We make no specific assumptions about the correlation of preferences across or within districts. In particular, we do not rule out the kind of correlation of preferences that might naturally arise because of sorting à la Tiebout.

\section{A. Federal Mandate Chosen by Referendum}

Voting takes place in two stages: first a federal mandate is chosen, and second each district chooses its own policy, constrained by this mandate. Voters are assumed to have no specific information about the other voters, and our results rely on dominant strategies.

Formally, the voting game is modeled as the following two-stage majoritarian game, in which at each stage each voter announces an ideal policy. The one-stage version of the game we use was first studied by

\footnotetext{
${ }^{2}$ There does exist a literature on the structure of overlapping regulatory authority, focusing on specific applications.
} 
Moulin (1980), who showed that a mechanism that chooses a policy that is the median of the declared favored policy of the voters is "straightforward," in the sense that it offers no opportunities for the voters to manipulate it, regardless of their belief about the strategies of other voters (see also Border and Jordan 1983).

Stage 1: Each voter announces a policy, $\hat{F}_{i d}$. A federal standard, $F$, is set equal to the median of the announced policies: $F=\operatorname{med}\left\{\hat{F}_{i d}\right\}$.

Stage 2: In each district, given the federal standard $F$ chosen in the first stage, each voter announces a proposed policy in $[F,+\infty)$, and the policy $x_{d}$ implemented in district $d$ is the median of the policies announced at this stage.

The key feature of this game is that outcomes are driven by the median voter in each stage. It is meant to represent outcomes resulting from competitive behavior under majority rule. Some minor variations on this rule could be used. For example, similar results are obtained if the outcome was determined by, say, $F=M / 2$ rather than $F=M$ or, more generally, if $F$ is any strictly increasing function of $M$. Voter equilibrium strategies would adjust to compensate for the difference.

To identify the equilibrium of this game, we first show that the second stage of this voting scheme is strategy-proof (it is an equilibrium to have all voters vote their ideal policy) for any outcome of the first stage. We then show that in the first stage players have a unique dominant strategy given that other players' reports in the second stage are truthful. ${ }^{3}$ This finding that in equilibrium voters do not strategically underreport their preferences in the first stage of the game (setting the federal mandate) plays a central role in driving our results.

We call this a sequentially dominant strategy equilibrium. We denote by $\left(F^{*}, x_{1}^{*}, \ldots, x_{D}^{*}\right)$ the equilibrium outcomes in the two stages and by $x_{d}^{*}(F)$ the equilibrium outcome of stage 2 in district $d$ if the outcome of stage 1 is $F$.

The unique equilibrium outcome of the game is described in the following theorem.

Theorem 1. The equilibrium outcome of the two-stage voting game is a standard equal to the mean of the types of all voters, $F^{*}=M$, and an outcome in each district equal to the maximum of $M$ and the district median, $x_{d}^{*}=\max \left\{M, m_{d}\right\}$.

This theorem states that at the federal stage, voters vote for their

\footnotetext{
${ }^{3}$ This equilibrium seems very natural, but there are other equilibria that are reasonable if we change our assumptions about the information of the voters. Assume, for instance, that in the first stage voters know $m_{d}$ precisely. Then, even if they predict sincere voting in the second stage, all votes in $\left[0, m_{d}\right]$ are undominated in the first stage of the game for voters whose type is smaller than $m_{d}$. We feel that the equilibrium used in this section, which requires minimum information from the voters, is the most reasonable selection. Using others would not affect our substantive conclusions.
} 
preferred policy, as though there were no second local stage: there is no strategic underreporting of preferences. The formal proof is presented in the Appendix, but its basic idea is simple. First, because preferences are single-peaked on $[F,+\infty)$, it is a dominant strategy for voters to vote for their ideal policy in the second stage of the game. In the first stage, if $t_{i d}>m_{d}$, then voter $(i, d)$ would like $F$ to be as close as possible to his or her ideal policy and cannot do better than voting truthfully in the first stage. (Recall that voters do not know whether $t_{i d}>m_{d}$ or $t_{i d}<m_{d \cdot}$ ) On the other hand, if $t_{i d}<m_{d}$, then voter $(i, d)$ cares only that $F$ be smaller than $m_{d}$, and in order to obtain this, he or she might as well vote $t_{i d}$. Hence, whatever the relationship between $t_{i d}$ and $m_{d}$, a voter cannot do better than voting $t_{i d}$.

Theorem 1 enables us to prove several interesting properties of the equilibria that help understand the consequences of the presence of a federal level.

Property 1. For every district, $x_{d}^{*} \geq m_{d}$, and for at least one district, $x_{d}^{*}>m_{d}$.

That is, the effect of federal mandates is to weakly increase the policy level in every district and strictly increase the policy in at least one district. The districts in which federal mandates lead to a strict increase are those low-demand districts with $m_{d}<M$. Because we have assumed that no two voters share the same ideal policy, that every district has an odd number of voters, and that there are at least three districts, there exists at least one low-demand district, with $m_{d}<M$, and hence $x_{d}>$ $m_{d}$.

We now turn to the consequences of these facts for the welfare of voters.

Property 2. Voters in high-demand districts in which $m_{d}>M$ are unaffected by a federal mandate.

In high-demand districts, the outcome $x_{d}^{*}=m_{d}$ is the same outcome that would arise without a federal mandate.

Property 3. A voter for whom $t_{i d} \leq m_{d}$ is made weakly worse off by a federal mandate. If $m_{d}<M$, this voter is made strictly worse off.

This property follows from the fact that federal mandates do not lower the policy in any district. A locally low-demand voter $\left(t_{i d}<m_{d}\right)$ would be better off only if the federal mandate actually lowered the local policy, which can never happen. If, in addition, this locally low-demand voter resides in a low-demand district, then the federal mandate produces a strict increase in the local policy, which makes the voter strictly worse off.

Property 4 . Voters for whom $m_{d}<M \leq t_{i d}$ are made strictly better off by a federal mandate.

The logic behind this is analogous to the logic behind property 3 , but with an additional twist. A locally high-demand voter $\left(t_{i d}>m_{d}\right)$ is 
made better off if the federal mandate raises the local policy, but only if it does not raise it too much. If this locally high-demand voter resides in a low-demand district, then the federal mandate produces a strict increase in the local policy, which makes the voter strictly better off, and if the voter's type is greater than the overall median, the federal mandate certainly increases his or her utility.

Property 5 . Voters for whom $m_{d}<t_{i d}<M$ may be either better off or worse off with a federal mandate.

If $m_{d}<t_{i d}<M$, the mandate produces an outcome greater than $t_{i d}$. Since preferences are single-peaked and $m_{d}$ and $M$ lie on opposite sides of voter $t$ 's ideal policy, the utility derived from policy $M$ (resulting from the federal mandate) can be either greater or less than the utility derived from policy $m_{d}$.

PROPERTY 6 . There are more voters that are made worse off by a federal mandate than there are voters that are made better off.

By property 2, voters in high-demand districts are unaffected by mandates. Therefore, only voters from low-demand districts are affected. From property 1 there is at least one low-demand district, and from property 3 more than half of the voters from such districts (those for whom $t_{i d} \leq m_{d}$ ) are made worse off.

Property 6 can be interpreted as a negative verdict on the welfare consequences of federal mandates in our framework. Given that the standard approach to constitutional design in economics and in social choice theory is to look for constitutions that maximize some measure of welfare, this result begs the question of the reason for the presence of federal mandates in the first place. One immediate answer is that it would be impossible to constitutionally rule out federal intervention in policy areas with little or no economic benefit to federal intervention while encouraging it in policy areas with greater economic benefits from intervention. The problem is simply that it is very difficult to provide ex ante a delimitation between those issues that are genuinely motivated by the presence of significant economic benefits from intervention and those issues that are not. In either case, "high-demand" voters would pressure for federal intervention. Thus, regardless of the care with which such lines would be drawn, some issues will be open to federal intervention even with minimal external benefits or economies. La Malène (1996/97) provides an example of this tendency of local political fights to spill over at the federal level. In 1994, the delegation for Europe of the French Chambre des Députés judged that a proposed European directive on poverty was contrary to the principle of subsidiarity. When a resolution to the effect came to the floor, it was impossible to direct the debate away from the substantial issues involved toward the constitutional aspects, and the Chambre approved the proposed directive. 


\section{B. Federal Mandate Chosen by a Representative Legislature}

We have assumed that the federal standard was chosen by a mechanism in which all voters from all districts vote. In many settings federal policies are actually chosen by representative legislative bodies. This will also lead to excessive federal intervention. In order to study this issue, we introduce a variation of our model in which each district elects a representative, and these representatives vote on the federal standard. This adds a stage to our basic game as follows:

Stage 1: Each voter announces a policy, and the median vote in each district is used as the district's vote for the federal mandate. ${ }^{4}$

Stage 2: The federal mandate, $F$, is given by the median of the median votes of each district.

Stage 3: In each district, each voter votes for a policy in $[F,+\infty)$, and the policy $x_{d}$ implemented in district $d$ is the median of the votes at this stage.

Because the third stage of the game is the same as above, it is still true that voters will vote for their ideal policy. We show in the Appendix that in the first stage (when they vote for their representative) voters still have a dominant strategy to vote for their true ideal policy. The intuition behind this result is very similar to the intuition behind theorem 1 . The only difference is that the interval in which the voter can move $F$ is determined by the district to which he or she belongs.

This implies that the federal standard is equal to the median of the median types of each district:

$$
M^{d}=\operatorname{med}\left(m_{1}, m_{2}, \ldots, m_{D}\right) .
$$

Theorem 2. Theorem 1 and properties $1-3$ hold, with $M$ replaced by $M^{d}$.

Depending on the distribution of types, $M^{d}$ can be smaller than, equal to, or greater than $M$. To see this, consider a simple example with three districts each containing three voters. Suppose that the ideal points are aligned as follows:

$$
t_{11}<t_{12}<t_{13}<t_{21}<t_{22}<t_{32}<t_{31}<t_{23}<t_{33} .
$$

Hence, $m_{d}=t_{2 d}$ for all $d$ (i.e., voter $(2, d)$ is the median voter in district $d)$ and $M=M^{d}=m_{2}=t_{22}$. Next, suppose that $t_{31}$ were the leftmost ideal point instead of the third from the rightmost ideal point. Then we would have $M=t_{21}<M^{d}=t_{22}$. Similarly, if $t_{13}$ were the rightmost ideal point instead of the third from the leftmost ideal point, then we would have $M=t_{32}>M^{d}=t_{22}$.

\footnotetext{
${ }^{4}$ One could also interpret this as the outcome of a competitive two-party election for a representative. The majority rule equilibrium outcome of such an election would be the same as the dominant strategy outcome of this game.
} 


\section{Substitution between Federal and Local Policy}

In this section, we study a particular application of federal mandates, in which there is a local public good that is provided by a combination of federal and local expenditures. There are many examples of this, such as police and public safety, education, and transportation infrastructure. While some of these applications involve more than two levels of government funding decisions, the basic ideas can be captured by a simple modification of our two-layer model of the previous section. This enables us to address questions about the relative efficiency of federal versus local provision of local public goods, a subject of much interest in the fiscal federalism literature.

\section{A. Perfect Substitution}

To avoid considerations of income redistribution, we assume that all citizens pay the same taxes. More precisely, all citizens of the federation pay the same federal taxes, and two citizens in the same district pay the same local taxes. Consider first a model in which the net utility of voter $(i, d)$ is

$$
u_{i d}\left(z_{d}\right)-\left(s+y_{d}\right),
$$

where $z_{d} \geq 0$ is the amount of public service in district $d, s \geq 0$ is the per capita federal tax, and $y_{d} \geq 0$ is the per capita local tax in district $d$. The utility function $u_{i d}$ is strictly concave, differentiable, and increasing. It satisfies the Inada conditions $u_{i d}^{\prime}(0)=+\infty$ and $\lim _{s \rightarrow+\infty} u_{i d}^{\prime}(s)=$ 0 .

Public services are produced thanks to federal and local expenditures, which are perfect substitutes: $z_{d}=s+y_{d}$.

If voter $(i, d)$ were a dictator, he would choose an amount of public service $t_{i d}$ that satisfies

$$
u_{i d}^{\prime}\left(t_{i d}\right)=1,
$$

and he would not care whether this was provided through federal or local funds. We assume that $t_{i d} \neq t_{\text {ild }}$ for all $(i, d) \neq\left(i^{\prime}, d^{\prime}\right)$.

The federal and local policies are chosen through the following twostage game:

Stage 1: Each voter announces a proposed federal policy, $\hat{s}$, and a federal policy $s$ is determined by $s=\operatorname{med}\left\{\hat{s}_{i d}\right\}$.

Stage 2: In each district, given the federal policy $s$ chosen in the first stage, voters announce a proposed local policy, that is, a total amount of public goods $z_{d} \geq s$ to be provided in district $d$. The district will have to raise per capita taxes $z_{d}-s$. The local policy $z_{d}$ that is implemented 
in district $d$ is the median of the policies proposed by its voters at this stage. ${ }^{5}$

It is straightforward to see that this game is strategically equivalent to the game studied in Section II. It is sufficient to think of $s$ as the federal standard and $s+y_{d}$ as the policy implemented in district $d$. Hence all the results discussed earlier hold.

A similar model would apply to "unfunded mandates," that is, federal laws that impose on local governments' minimum expenditures. It is sufficient to reinterpret $s$ as the level of these unfunded mandates.

\section{B. Local Provision Less Efficient than Public Provision}

Up to now, we have worked with models in which there exists no reason to have a federal policy. Federal expenditures are sometimes defended on the grounds that they are more efficient than local expenditures. For instance, while discussing the decentralization of investment of infrastructure in developing countries, Smith and Shin (1995) write that "many infrastructure activities require large capital investments and exhibit significant scale economies. Some decentralized jurisdictions may be smaller than the minimum efficient size for particular activities" (p. $55)$.

To study the implications of such efficiency differences, we modify the utility function (2) and assume that it is of the type

$$
u_{i d}\left(s+\alpha y_{d}\right)-\left(s+\beta y_{d}\right),
$$

where $\alpha \in(0,1]$ represents the relative efficiency of local spending compared to public spending (a dollar of local spending increases the production of public goods by only $\alpha$ dollars) and $\beta \geq 1$ represents the relative efficiency of local tax collection (a dollar of local tax collection decreases welfare by $\beta$ dollars).

We assume that at least one of the two inequalities $\alpha<1$ and $\beta>1$ holds, so that there are positive reasons for federal expenditures. Otherwise, the game proceeds in the same way as in Section IIIA.

It is convenient to define two "types" for voter $(i, d)$ : a federal type

$$
t_{i d}^{f}=\arg \max _{z}\left[u_{i d}(z)-z\right]
$$

which is his or her preferred level of public services if they were provided exclusively with federal funds, and a local type

\footnotetext{
${ }^{5}$ We would obtain the same results if voters voted on per capita local expenditures $y_{d^{*}}$ Our formulation simplifies the analysis of Sec. IIIB.
} 


$$
t_{i d}^{l}=\arg \max _{z}\left[u_{i d}(z)-\beta \frac{z}{\alpha}\right],
$$

which is his or her preferred supplies of public services if they were provided exclusively with local funds. We have

$$
u_{i d}^{\prime}\left(t_{i d}^{l}\right)=\frac{\beta}{\alpha}>1=u_{i d}^{\prime}\left(f_{i d}^{f}\right),
$$

which, by concavity of $u_{i d}$, implies $t_{i d}^{l}<t_{i d}^{f}$. We assume that the $t_{i d}^{l}$ 's and the $t_{i d}^{f}$ 's are all different from each other.

If the federal standard is $s$, the preferred local policy of voter $(i, d)$ is $\max \left(s, t_{i d}^{l}\right)$, which implies local expenditures equal to $\max \left(0, t_{i d}^{l}-\right.$ s).

The following lemma states formally the fact that any voter prefers that whatever level of public service is implemented be implemented as much as possible through federal spending.

Lemma 1. If $s+\alpha y_{d}=s^{\prime}+\alpha y_{d}^{\prime}=z_{d}$ and $s>s^{\prime}$, we have

$$
u_{i d}\left(z_{d}\right)-\left(s+y_{d}\right)>u_{i d}\left(z_{d}\right)-\left(s^{\prime}+y_{d}^{\prime}\right) .
$$

Proof. We have

$$
y_{d}^{\prime}=\frac{z_{d}-s^{\prime}}{\alpha}>\frac{z_{d}-x}{\alpha}=y_{d}
$$

and therefore $s+\beta y_{d}<s^{\prime}+\beta y_{d}^{\prime}$. Q.E.D.

It is clear that, given any federal standard, $s$, chosen in the first stage, every voter has a dominant strategy to vote for a local policy equal to $\max \left(s, t_{i d}^{l}\right)$ in the second stage of the game. Note that a voter could wish that federal expenditures were higher and still not vote for additional local expenditures, since increasing public services through local funds is more expensive than increasing them through federal funds. This implies that given a federal policy $s$, the policy implemented in district $d$ is

$$
\operatorname{med}\left[\max \left(s, t_{i d}^{l}\right)\right]=\max \left(s, m_{d}^{l}\right),
$$

where $m_{d}^{l} \equiv \operatorname{med}\left(t_{i d}^{l}\right)$.

Since this expression depends on the median in district $d$, we need to modify slightly our assumption about what each voter knows. Specifically, we assume that voters know the median ideal point of the other voters in their district. We are now ready to prove the following theorem, which describes the first-stage strategy of the voters.

Theorem 3. In the first stage, the unique dominant strategy of voter $(i, d)$ is to vote for the policy $\max \left(m_{d}^{l}, t_{i d}^{f}\right)$.

The details of the proof are provided in the Appendix, but its basic 
idea can be sketched quite easily. Fix all votes except that of $(i, d)$ and let $\left[s^{-}, s^{+}\right]$denote the range of policies that can be median outcomes for all possible votes $(i, d)$ could submit. If $m_{d}^{l} \notin\left[s^{-}, s^{+}\right]$, the outcome will in any case be $F$. It is in the interest of the voter to make $F$ as close to $t_{i d}^{f}$ as possible, which he can do by the rule above. If $m_{d}^{l} \in\left[s^{-}, s^{+}\right]$, the voter can force any local policy in the interval $\left[m_{d}^{l}, s^{+}\right]$and therefore can do no better than the rule above. Uniqueness is established by showing that for any other rule there exists some configuration of other voters that would make that other rule suboptimal.

The following technically obvious corollary states that changes that on efficiency grounds should favor the substitution of local expenditures for federal expenditures have the exact opposite effect.

Corollary 1. As local expenditures become more efficient, that is, as $\beta$ decreases or $\alpha$ increases, the equilibrium federal standard $F$ increases.

In particular, as both $\alpha$ and $\beta$ converge to one, both the federal type $t_{i d}^{f}$ and the local type $t_{i d}^{l}$ of voter $(i, d)$ converge to $t_{i d}$, as defined by equation (3), and voter $(i, d)$ 's vote converges to $\max \left(m_{d}, t_{i d}\right)$. This implies, in particular, that the limiting federal standard is greater than or equal to both $M$ and $M^{d}$. For instance, if the $t_{i d}$ 's satisfy (1), it is equal to $M=M^{d}$. On the other hand, if

$$
t_{11}<t_{12}<t_{13}<t_{21}<t_{22}<t_{32}<t_{31}<t_{23}<t_{33} \text {, }
$$

then $M=M^{d}=m_{2}=t_{22}$, whereas the limit federal standard is $t_{32}$.

This suggests that it will be difficult to establish general welfare results about federal standards: clearly in this case there are good reasons to have federal standards. However, if we aggregate welfare, when $\alpha$ and $\beta$ are close to one, the optimal federal policy is basically equal to the lowest median types among all the districts, but, as shown in the previous paragraph, the equilibrium policy will be much larger than this. The next section studies the welfare effects of federal mandates in more detail.

\section{The Welfare Effects of Federal Mandates}

In this section, we consider two examples in order to make specific welfare comparisons between three different federal/local fiscal regimes: (1) only local provision, (2) only federal provision, and (3) mixed provision (both federal and local). The aim of the examples is to illustrate the range of effects induced by the presence of two levels of government.

To simplify the calculations, we approximate a large number of voters in a large number of districts by assuming a continuum of districts and a continuum of voters. We assume that the conditional measure of voters 
is the same in each district, so that each district is effectively the same size.

Districts differ from each other only by the distribution of ideal policies: The net utility functions of all voters have the quasi-linear form

$$
i \ln \left(s+y_{d}\right)-\left(s+\beta y_{d}\right),
$$

where, as explained in Section III, $s$ is the per capita level of the public good provided by the federal government in each district, and $y_{d}$ is the per capita level of the public good locally provided by district $d$. The preferences of agent $(i, d)$ do not depend on his district (but the distributions of $i$ will differ among districts), and $i$ indexes his or her strength of preference for the public good. We refer to $i$ as the type of voter $(i, d)$. Below, we explore how federal and local expenditures vary as a function of $\beta$ and of the distribution of preferences within and across districts.

We shall see that the distributions of types within and between districts affect crucially the relative social welfare induced by the three different possible constitutions. Furthermore, the social welfare in the constitution with both a federal and a local level does not vary monotonically with $\beta$. Indeed, an increase in $\beta$ has two effects, which work in opposite directions: (1) it decreases welfare by making local provision of public goods more expensive, and (2) it increases welfare by diminishing the upward distortion to $s$.

\section{A. Example 1}

The parameter $d$, which indexes districts, is uniformly distributed on $[0,1]$. In district $d$, voter types (i.e., the $i$ 's) are distributed uniformly on the interval $(0, d]$. To compare the different regimes, we first use the results of the previous section to derive the induced preferences and voting behavior under the three regimes. Then we compare the expected welfare of each regime as a function of the efficiency parameter, $\beta$, by integrating over the distribution of districts and types. Details of the computation are given in the Appendix.

Induced preferences.-Regime 1 (local): Voter $(i, d)$ 's ideal point is $i / \beta$. Regime 2 (federal): Voter $(i, d)$ 's ideal point is $i$. Regime 3 (mixed): Voter $(i, d)$ has a dominant strategy in the first round equal to $\max [i, d / 2 \beta]$ since $(i, d)$ 's district median is equal to $d / 2 \beta$. Given $s$, the outcome of the first round, he or she has a dominant strategy in the second round equal to $\max [(i / \beta)-s, 0]$.

District outcomes.-Given the induced preferences and voting behavior, the equilibrium district outcomes in the three regimes are as follows: Regime 1 (local): $s=0$, and $y_{d}=d / 2 \beta$. Regime 2 (federal): $s \equiv$ overall median $\approx 0.19$, and $y_{d}=0$. Regime 3 (mixed): If $\beta<2.67$, then 


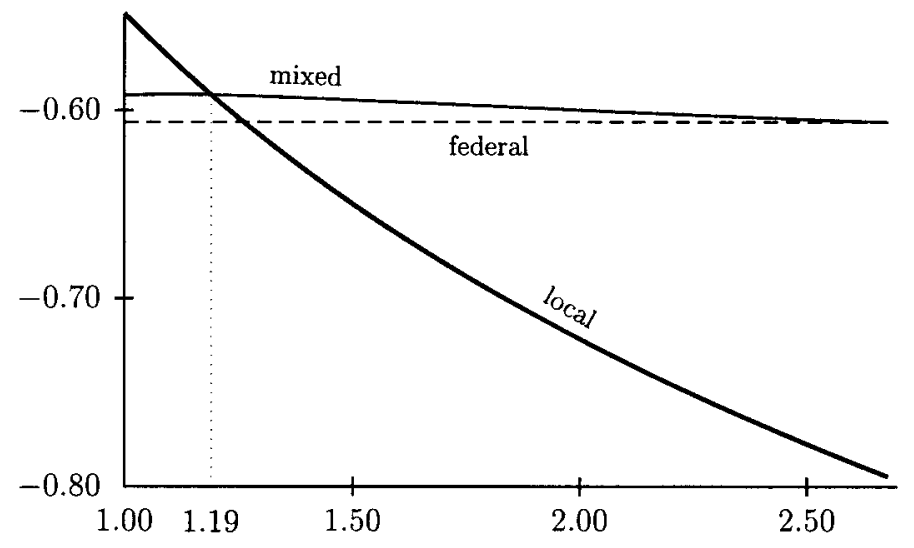

Fig. 1.-This figure shows the social welfare associated with the three possible constitutions in example 1. The thick line represents the welfare of a "local governments" only constitution, the dashed horizontal line that of a "central government" only constitution, and the continuous thin line that of a mixed system of government.

$$
s=\frac{1}{\ln (2 \beta e)}
$$

and

$$
y_{d}=\max \left[\frac{1}{\ln (2 \beta e)}, \frac{d}{2 \beta}\right] .
$$

If $\beta>2.67$, then $s \approx 0.19$ and $y_{d}=\max [0.19, d / 2 \beta]$.

Aggregate welfare.-The comparison of aggregate welfare under the three regimes is shown in figure 1, which illustrates four points. First, the regime with only federal spending is never optimal. Second, if federal spending is only slightly more cost-efficient than local spending, then the "only local" regime is optimal. Third, if the cost advantage of federal spending is sufficiently great, then the mixed regime is optimal. Fourth, in the mixed regime, welfare is not monotonic in $\beta$.

\section{B. Example 2}

In example 1, the distribution of types is skewed toward low levels. In this example, we consider a distribution of types that is symmetric around 0.50 . Districts are indexed by $d$, uniformly distributed in $[0$, $0.50]$. Within each district, voters are indexed by $i \in[d, d+0.50]$. Utility functions are the same as in example 1; therefore, our two examples 


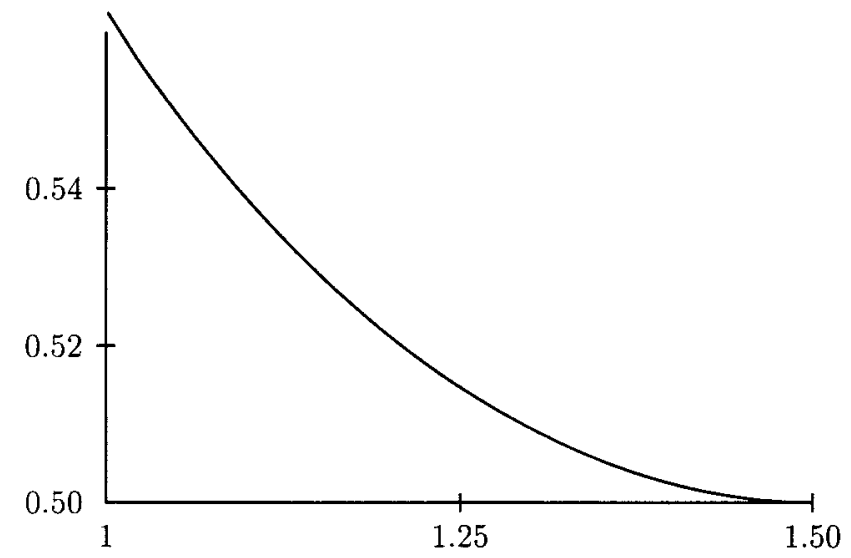

FIG. 2.-The equilibrium level of federal expenditures in the mixed system as a function of $\beta$ in example 2 .

share the same basic structure of preferences but have a different distribution of types.

Federal.-The distribution of the types of voters is triangular, and the median vote with only federal provision is 0.50 . Aggregate welfare is -0.85 .

Local.-If there is only local provision, the median vote in district $d$ is $(d+0.25) / \beta$ and aggregate welfare is $-0.83-0.50 \ln \beta$. Therefore, only federal provision is better than only local provision if and only if $-0.85 \geq-0.83-0.50 \ln \beta$ (which is equivalent to $\beta \geq 1.04$ ), which is true unless local provision is almost as efficient as federal provision.

Mixed.-The vote of a type $i$ voter in district $d$ at the federal level is $\max [i,(d+0.25) / \beta]$. The minimum possible vote is therefore $1 / 4 \beta$. Voter $(i, d)$ votes for a level of public expenditures less than or equal to $v$ if and only if

$$
v \geq \max \left[i, \frac{d+0.25}{\beta}\right] \Longleftrightarrow\{i \leq v \text { and } d \leq v \beta-0.25\} .
$$

One can show that if $\beta \geq 1.5$, the outcome is equivalent to only federal provision. The equilibrium level of federal expenditures for $\beta \in$ $[1,1.5]$ is graphed in figure 2.

Aggregate welfare.-The shape of aggregate welfare as a function of $\beta$ is shown in figure 3 . When $\beta$ increases, welfare first decreases and then increases, which is the opposite of example 1 . Also in contrast to example 1 , provision at both the local and federal levels is always dominated by 


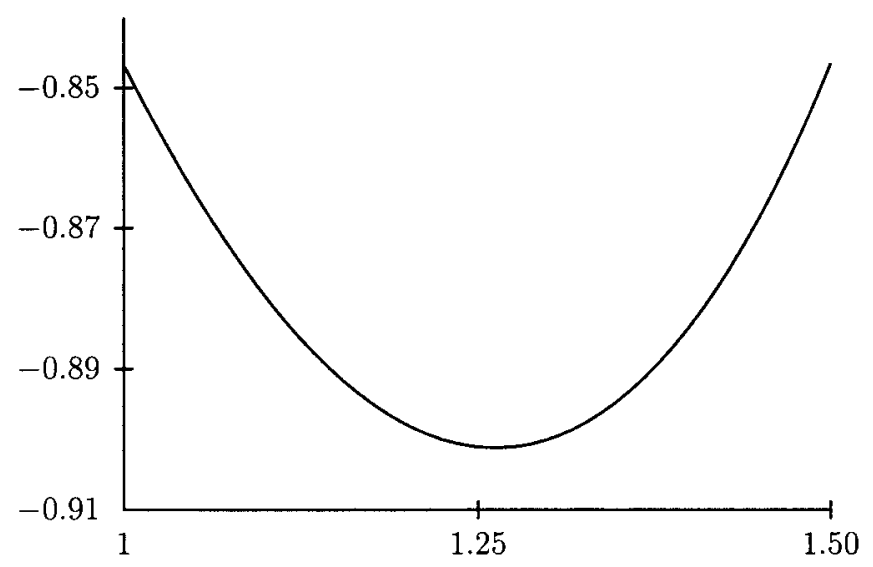
2.

provision only at the federal level (and a fortiori by the best of provisions only at the local level or only at the federal level).

\section{Conclusion}

In this paper, we have explored a new framework for studying the political economy of federal mandates. The basic insight is that even though voters are forward-looking and anticipate the effects of a federal mandate in changing local policy, incentives under majority rules may lead to adoption of federal mandates that make more voters worse off than better off. Local districts that would have a high policy level anyway are unaffected, but voters from districts that would have adopted a low level of provision of the local public good are made worse off. Surprisingly, the loss of efficiency due to the presence of a federal government can be even greater when federal provision of the public good is more efficient than local provision. Of course, our model abstracts from many features of reality, such as the roles of politicians or of interest groups. At the very least, we show that those groups that have a private interest in concentrating power at the federal level find a powerful ally in the voting behavior of the electorate.

We plan to extend our simple model in a number of directions. First, we shall allow for externalities between districts; that is, the utility of voter $(i, d)$ will be of the type $u_{i d}\left(y_{1}, \ldots, y_{D}\right)-y_{d}$. In this case, local decisions are strategically linked to each other since voter preferences are contingent on the policy decisions of other districts, and the formal 
analysis is significantly complicated. Second, we would like to introduce in the model local agenda-setting monopolists à la Romer and Rosenthal (1979), who argue that proposal power for local referenda rests in the hands of bureaucrats who have preferences that differ from those of the median voter. Then one can show that federal mandates determined by majority rule can dilute the power of local agenda-setting "policy monopolists" since policy monopolists need a low-status quo policy in order to give them agenda power. Federal mandates effectively raise the status quo, which reduces (in some cases completely nullifying) leverage of local policy monopolists, leading to a moderation of local policies (Crémer and Palfrey 1999a). A third interesting extension is to allow voters to vote with their feet as well as in the voting booth, as in the Tiebout model of interjurisdictional equilibrium. This will make the preferences in each district more homogeneous and presumably alter the incentives of low-demand districts to accept federal mandates, since a very large proportion of their electorate would oppose them.

More generally, this paper is part of a larger research program in which we are attempting to study the interplay between politics at the local level and at the federal level. In previous work (Crémer and Palfrey 1996, 1999b), we study the constitutional stage in this light. We show that citizens will vote to transfer power from the local to the federal level after determining in which of these two levels their views are more likely to prevail. In the present paper, we assume that power has already been allocated between governmental levels and show how voters will use federal mandates in order to impose their preferred policies locally. This approach is in sharp contrast with most of the literature on federalism, in both economics and political science. In economics, the study of federalism, whether in the fiscal federalism literature or in the more recent regulation-type literature, models the local level through a representative agent. Only in Tiebout-type models does the difference in the tastes of the voters play a role, but the objective of the local government is given exogenously. In any case the equilibrium homogenizes the tastes of the local population.

Peterson (1995) presents a useful summary of the political science literature, which he divides into two strands. The "functional theory," based on normative principles, assumes that the allocation of responsibilities is meant to manage externalities as efficiently as possible. Redistribution, which is a federal responsibility, plays an important role in the analysis. It does assume that citizens are different, but this is not exploited to study conflicts between citizens, at either the local or federal level. The "legislative theory," on the other hand, stresses the way in which legislators try to serve the interests of their voters, in particular, by maximizing the amount of pork barrel allocated to their districts, which have a homogeneous population. 
Taking into consideration seriously the politics of the functioning of a federal system, as we are trying to do, opens up a host of questions and should eventually force a reconsideration of the theory of allocation of responsibilities between different levels of government. For instance, we have shown that it is in general detrimental to allow federal intervention when there is little or no efficiency reason for doing so. However, as argued in Section IIA, it is practically impossible to prevent in practice, and some issues will be open to federal intervention even with minimal external benefits or economies. A deeper study of this "delimitation problem" would be very valuable and could help provide a bridge between previous normative approaches and our positive approach. This would require a model with multiple issues and an equilibrium in which some issues involve federal intervention and others do not.

\section{Appendix}

\section{A. Proof of Theorem 1}

Theorem 1 is an immediate consequence of the following two lemmas.

Lemma A1. For any $F$, voter $(i, d)$ has a unique dominant strategy in the second stage of the voting game: voting for his or her favorite policy on $[F,+\infty)$. As a consequence, $x_{d}^{*}(F)=\max \left\{F, m_{d}\right\}$ for all $F$ and $d$.

Proof. The issue space is one-dimensional, and preferences of the voters are single-peaked over $[F,+\infty)$. Therefore, the standard results on majority voting apply (see, e.g., Moulin 1980; Border and Jordan 1983). Q.E.D.

To save on notation, we denote the ideal policy of voter $(i, d)$ by $t$.

Lemma A2. Voting $t$ is the unique dominant strategy in the first stage of the voting game for voter $(i, d)$.

Proof. The strategy of the proof is to show that voter $(i, d)$ has a dominant strategy of voting $t$ if $t \geq m_{d}$ and also has a dominant strategy of voting $t$ if $t<$ $m_{d}$. Therefore, the voter has a dominant strategy of voting $t$ even though he or she does not know $m_{d}$.

Case 1: $t \geq m_{d}$. Denote by $\left[t^{-}, t^{+}\right]$the interval in which the voter can make the federal standard vary through the choice of his or her vote, given the profile of other votes. That is, $t^{-}$is the $(N-1) / 2$ th largest vote among the votes of the other voters and $t^{+}$is the $(N+1) / 2$ th largest vote among the votes of the largest voters, where $N$ is the total number of voters. To show that voting $t$ is a dominant strategy, we show that whatever $t^{-}$and $t^{+}$, voting $t$ is an optimal strategy. If $t^{-}=t^{+}$, then the voter has no influence on the vote, and voting $t$ is optimal. Assume, therefore, that $t^{-}<t^{+}$, and consider the following cases. (a) $t<t^{-}$: In this case, the best possible federal standard the voter can obtain is $t^{-}$, which results from voting $t$. (b) $t \in\left[t^{-}, t^{+}\right]$: In this case, the voter can obtain the federal standard $F=t$ by voting $t$, which will result in outcome $t$ for district $d$, since $\max \left\{F, m_{d}\right\}=\max \left\{t, m_{d}\right\}=t$. (c) $t>t^{+}$: In this case, the best possible federal standard the voter can obtain is $t^{+}$, which results from voting $t$.

To see that voting $t$ is the only dominant strategy, assume first that the voter chooses a vote $v>t$. Suppose that the profile of other votes yields an interval $\left[t^{-}, t^{+}\right]$such that $t<t^{-}<t^{+}<v$. In this case voter $(i, d)$ will obtain the outcome $t^{+}$, which is worse than what he or she could have obtained by voting $t$. Alternatively, suppose that voter $(i, d)$ had voted $v<t$ and the profile of other votes 
yields $t^{-}<t<t^{+}$. Then the outcome is $\max \left\{v, m_{d}\right\}<t$, whereas voting $t$ would have resulted in $t$.

Case 2: $t<m_{d}$. For any vote $v \leq m_{d}$, the outcome of the two-period game is $\max \left(m_{d}, t^{-}\right)>t$, so voting $t$ yields the same outcome as any other $v \leq m_{d}$. Therefore, suppose that $v>m_{d}$. There are four possible subcases. First, if $t^{-}=t^{+}$, then voting $t$ or $v$ yields the same outcome. Second, if $t^{-}<t^{+} \leq m_{d}$, then the outcome is $m_{d}$ whether voter $(i, d)$ votes $t$ or $v$, so $t$ is at least as good a voting strategy as $v$. Third, if $t^{-}<m_{d}<t^{+}$, then voting $v$ is strictly worse than voting $t$. Finally, if $m_{d}<t^{-}<t^{+}$, then voter $(i, d)$ obtains $t^{-}$by voting $t$ and obtains $\max \left(v, t^{-}\right) \geq$ $t^{-}$by voting $v$, so voting $t$ is at least as good as voting $v$.

To see that voting $t$ is the only dominant strategy, consider any $v>t$ and some profile of other votes yielding $\left[t^{-}, t^{+}\right]$, such that $m_{d}<t<t^{-}<t^{+}<v$. In this case the outcome would be $t^{+}$, which is worse than $t^{-}$, which he could have obtained by voting $t$, a contradiction. Alternatively, consider $v<t$ and some profile of other votes yielding $t^{-}<m_{d}<t<t^{+}$. Then the outcome is $\max \left\{v, m_{d}\right\}<t$, whereas voting $t$ would have resulted in the voter's ideal policy, a contradiction. Q.E.D.

\section{B. Proof of Theorem 2}

Theorem 2 is a direct consequence of the following lemma.

Lemma A3. Voting $t$ is the unique dominant strategy in the first stage of the voting game for voter $(i, d)$, given that $F$ is determined by the median of the median votes of the first stage.

Proof. Fix a voter $(i, d)$ and define $F^{-}$to be equal to the $(D-1) / 2$ th highest median of votes in the other districts, and $F^{+}$to be equal to the $(D+1) / 2$ th highest median of votes in the other districts. Voters of district $d$ can by their vote induce any outcome in the interval $\left[F^{-}, F^{+}\right]$. Let $t_{d}^{-}$be the $\left(n_{d}-1\right) / 2$ th highest vote of the other voters in district $d$ and $t_{d}^{+}$be the $\left(n_{d}+1\right) / 2$ th highest vote of the other voters in district $d$, where $n_{d}$ is the number of voters in district $d$. Whatever his vote, voter $(i, d)$ cannot move the median vote in district $d$ outside of the interval $\left[t_{d}^{-}, t_{d}^{+}\right]$.

If $\left[F^{-}, F^{+}\right] \cap\left[t_{d}^{-}, t_{d}^{+}\right]=\varnothing$, voter $(i, d)$ cannot affect the outcome $s_{d}$ by his vote in the first round, so voting $t$ is weakly optimal.

If $\left[F^{-}, F^{+}\right] \cap\left[t_{d}^{-}, t_{d}^{+}\right] \neq \varnothing$, let $t^{-}=\max \left\{F^{-}, t_{d}^{-}\right\}$and $t^{+}=\min \left\{F^{+}, t_{d}^{+}\right\}$. Then $\left[F^{-}, F^{+}\right] \cap\left[t_{d}^{-}, t_{d}^{+}\right]=\left[t^{-}, t^{+}\right]$. By changing his or her vote in the first round, voter $(i, d)$ can effectively choose any federal standard in the interval $\left[t^{-}, t^{+}\right]$, and the same arguments as in the proof of lemma A2 carry through. Q.E.D.

\section{Proof of Theorem 3}

Let us call $t^{-}$the smallest federal policy that voter $(i, d)$ can obtain and $t^{+}$the largest one, and consider the following cases. (By the assumptions that all types are different, we need consider only strict inequalities.)

Case 1: $m_{d}^{l}<t^{-}$. Whatever $(i, d)$ 's vote, the local policy will be equal to the federal policy. (a) If $t_{i d}^{f}<t^{-}$, the voter would like the federal policy to be $t^{-}$. Any vote less than or equal to $t^{-}$, in particular $\max \left(m_{d}^{l}, t_{i d}^{f}\right)$, will obtain this result. (b) If $t_{i d}^{f}>t^{+}$, the voter would like the federal policy to be $t^{+}$. Any vote greater than or equal to $t^{+}$, in particular $t_{i d}^{f}=\max \left(m_{d}^{l}, t_{i d}^{f}\right)$, will obtain this result. $(c)$ If $t^{-}<t_{i d}^{f}<t^{+}$, the voter can obtain his or her preferred policy-a level of public service equal to $t_{i d}^{f}$ entirely paid out of federal funds-by voting $t_{i d}^{f}=$ $\max \left(m_{d}^{l}, t_{i d}^{f}\right)$

Case 2: $m_{d}^{l}>t^{+}$. Whatever $(i, d)$ 's vote, the local policy will be $m_{d}^{l}$. By lemma 
1 , the voter would like federal spending to be as high as possible, that is to say, equal to $t^{+}$. He can obtain this by voting for the policy $\max \left(m_{d}^{l}, t_{i d}^{f}\right) \geq m_{d}^{l}>t^{+}$.

Case 3: $m_{d}^{l} \in\left(t^{-}, t^{+}\right)$. The voter can choose any local policy in the interval $\left(m_{d}^{l}, t^{+}\right)$. Because these policies are also implementable as federal policies, voter $(i, d)$ will want to ensure that they are and hence will choose a federal policy in that interval: (a) If $t_{i d}^{f}<m_{d}^{l}$, the best attainable policy for the voter is $m_{d}^{l}$, which can be obtained by voting $m_{d}^{l}=\max \left(m_{d}^{l}, t_{i d}^{f}\right)$. (b) If $t_{i d}^{f}>t^{+}$, the best attainable policy for the voter is $t^{+}$, which can be obtained by voting $t_{i d}^{f}=\max \left(m_{d}^{l}, t_{i d}^{f}\right) .(c)$ If $t_{i d}^{f} \in\left(m_{d}^{l}, t^{+}\right)$, the best attainable policy for the voter is $t_{i d}^{f}$, which can be obtained by voting $t_{i d}^{f}=\max \left(m_{d}^{l}, t_{i d}^{f}\right)$.

This proves that we have identified a first-stage dominant strategy equilibrium.

We must still prove that there is only one dominant strategy equilibrium.

1. Consider first the case $m_{d}^{l}<t_{i d}^{f}:(a)$ Assume that the vote $v$ of voter $(i, d)$ is strictly greater than $t_{i d}^{f}$. Then if $t_{i d}^{f}<t^{-}<t^{+}<v$, the federal policy would be $t^{+}$, which is farther away from his preferred federal (and local) policy $t_{i d}^{f}$ than $t^{-}$, which would have been chosen if he had voted $\max \left(m_{d}^{l}, t_{i d}^{f}\right)$. (b) If $v<t_{i d}^{f}$, the voter would obtain a suboptimal policy, $v$, whereas he could have obtained his first-best optimal federal policy, $t_{i d}^{f}$, when $v<t^{-}<t_{i d}^{f}<t^{+}$.

2. Consider next the case $t_{i d}^{f}<m_{d}^{l}:$ (a) If $m_{d}^{l}<v$, the voter would force a federal policy greater than $m_{d}^{l}$ if $m_{d}^{l}<t^{-}<v$, whereas he could have obtained the federal policy $m_{d}^{l}$, which is closer to his preferred policy $t_{i d}^{f}$, by voting $m_{d}^{l}=$ $\max \left(m_{d}^{l}, t_{i d}^{f}\right)$. (b) If $v<m_{d}^{l}$, the local policy will be $m_{d}^{l}$, as it would be if $v$ had been equal to $m_{d}^{l}$. However, if $v<t^{-}<t^{+}<m_{d}^{l}$, the federal policy would be $t^{-}$, whereas we know from lemma 1 that the voter would prefer it to be $m_{d}^{l}$, which it would be if he or she had voted $m_{d}^{l}$.

This proves the result.

\section{Computations for Example 1}

Induced preferences.- - If the public good were provided entirely at the federal level $\left(y_{d}=0\right)$, voter $(i, d)$ would vote for a level of federally funded public goods

$$
s^{* F}(i)=\arg \max _{s \geq 0} i \ln s-s=i .
$$

Given a level of public funding $s$, voter $(i, d)$ 's preferred local provision of public goods is $s^{* L}(i)=\max \{(i / \beta)-s, 0\}$. From the results of the previous section, given a level $s$ of federally funded public goods $s$, the level of public goods in district $d$ will be equal to $\max [s, d / 2 \beta]$. Therefore, voter $(i, d)$ 's dominant strategy in the first round is to vote for a level of federal expenditures equal to $\max [i, d / 2 \beta]$.

Only federal provision.-If there were provision only at the federal level, the outcome would be the median of the preferred level of public goods, taken over all voters. One finds $s^{6} s^{*} \simeq 0.19$, and by integration an aggregate social welfare of -0.61 .

Only local provision.-If there were only local provision, district $d$ would have a level of public good equal to $d / 2 \beta$. By integration, one computes the average welfare in district $d$, which is equal to $[d \ln (d / 2 \beta e)] / 2$, and aggregate social welfare, which is (approximately) equal to $-0.55-0.25 \ln \beta$. Therefore, it is

${ }^{6}$ All numerical calculations were done through the Maple engine integrated in Scientific WorkPlace. 


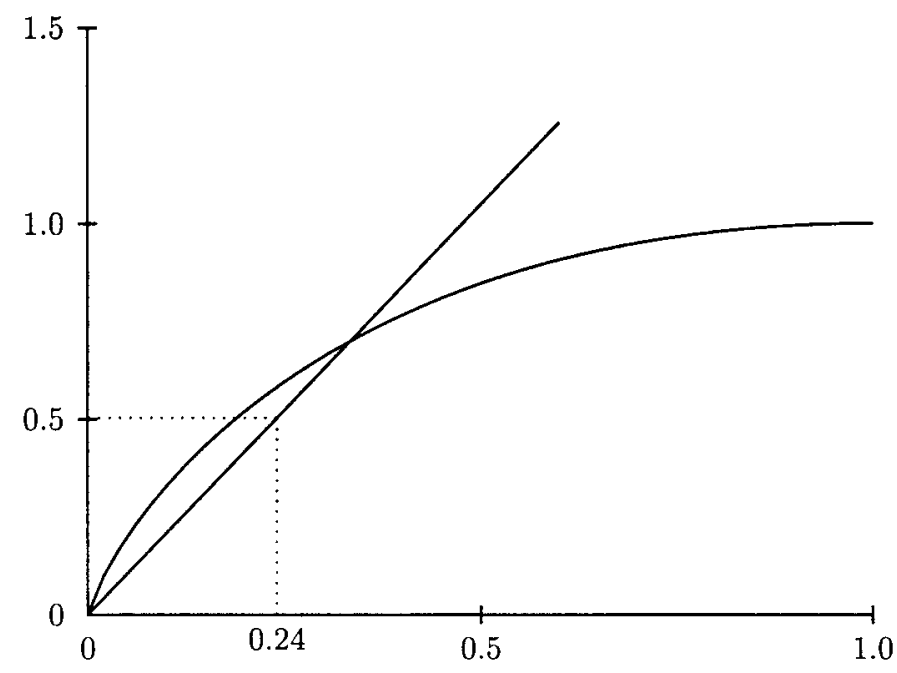

Fig. A1.-Distribution of votes for federal expenditures in example 1

better to have only a local level than only a federal level if $\beta \leq 1.26$ (see fig. 1 in the text).

Provision at both the federal and local levels.-We begin by computing the distribution of votes for federal expenditures. Let $G(v)$ be the measure of voters who will vote for federal expenditures less than or equal to $v \in[0,1]$ : (1) All the voters in districts such that $d \leq v$ have a vote less than or equal to $v$. This is a total measure of $v$ voters. (2) In districts such that

$$
\frac{d}{2 \beta} \leq v<d \Longleftrightarrow v \leq d \leq 2 \beta v,
$$

a proportion $v / d$ of the voters have a vote less than or equal to $v$ (in these districts a voter has a vote less than or equal to $v$ if and only if $i \leq v$ ). There are two subcases: $(a) 2 \beta v \geq 1$ : All districts satisfy $d \leq 2 \beta v$. Hence the measure of voters in these districts is equal to the integral with respect to $d$ of $v / d$ between $v$ and one, that is, $-v \ln v .(b) 2 \beta v<1$ : In this case the measure of voters is equal to the integral with respect to $d$ of $v / d$ between $v$ and $2 \beta v$, that is, $-v \ln 2 \beta$. (3) In districts such that $v<d / 2 \beta$, for all $i$ we have $\max [i, d / 2 \beta]>v$; hence there will be no vote less than or equal to $v$.

Putting this all together yields

$$
G(v)=v \ln \left[e \min \left(2 \beta, \frac{1}{v}\right)\right] .
$$

In figure $\mathrm{A} 1$ we graph $G(v)$ for the case of $\beta=1.50$. The horizontal axis is a level of federal expenditure, and the vertical axis the proportion of voters who will have a vote smaller than this level.

The curved line is $y=v-v \ln v=v \ln (e / v)$ and the straight line is $y=$ 


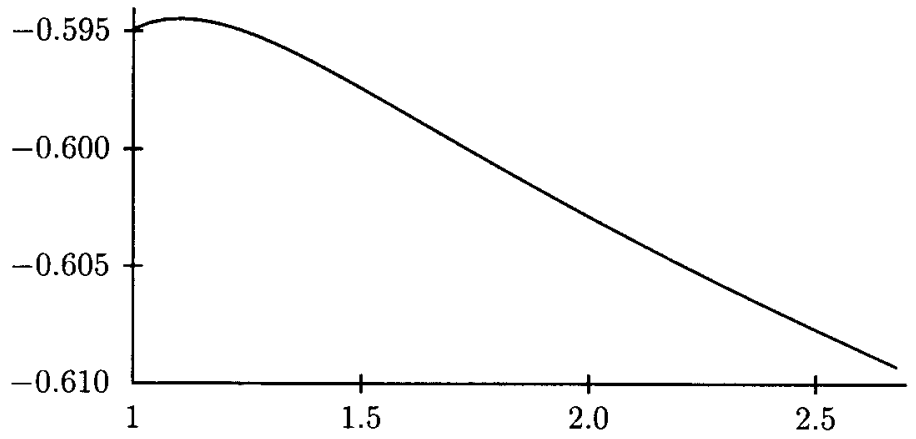

Fig. A2.-Variation in aggregate welfare as a function of $\beta$ in example 1

$v \ln (2 \beta e)$, so that $G(v)$ is the lower envelope of these two curves. In equilibrium, the outcome of the first stage is the policy for which $G(v)=0.50$, that is, the solution to $v^{*} \ln (2 \beta e)=0.50$, which is $v^{*}=0.24$ when evaluated at $\beta=1.50$. Notice that as $\beta$ decreases, that is, as local expenditures become more efficient, the straight line rotates toward the right and the level of federal expenditures increases! Similarly, as $\beta$ increases, the straight line rotates toward the left and the level of federal expenditures decreases, up to the unique value of $\beta^{*}>1$ such that $s \ln \left(2 \beta^{*} e\right)=s \ln (e / s)=0.5$. For values of $\beta$ lower than $\beta^{*}, s^{*}$ is constant and is given implicitly as the unique root of $\sin (e / x)=0.50$ in the region $[0,1]$, or approximately $s^{*}=0.19$. Solving numerically gives $\beta^{*}=2.68$. Aggregate social welfare under the mixed regime is obtained by integrating the expected welfare over all districts, and figure A2 shows its variation as a function of $\beta$. Notice that welfare is not necessarily decreasing in $\beta$ as discussed in the Introduction: when it is small, welfare increases with $\beta$. That is, greater cost efficiency (at the local level) can lead to lower aggregate welfare.

The computations for example 2 are very similar in spirit and are available in a previous version of the paper, which the authors will be happy to provide on request.

\section{References}

Bednar, Jenna. "The Credit Assignment Problem: A New Look at Political Competition and a Theory of Federal Encroachment." Manuscript. Iowa City: Univ. Iowa, Dept. Polit. Sci., 1998.

Border, Kim C., and Jordan, J. S. "Straightforward Elections, Unanimity and Phantom Voters." Rev. Econ. Studies 50 (January 1983): 153-70.

Crémer, Jacques, and Palfrey, Thomas R. "In or Out? Centralization by Majority Vote." European Econ. Rev. 40 (January 1996): 43-60.

_ . "Federal Mandates with Local Agenda-Setters." Manuscript. Pasadena: California Inst. Tech., 1999. (a)

—. "Political Confederation." American Polit. Sci. Rev. 93 (March 1999): 69-83. (b)

de Figueiredo, Rui J. P., and Weingast, Barry. "Self-Enforcing Federalism: Solving 
the Two Fundamental Dilemmas." Manuscript. Stanford, Calif.: Stanford Univ., Dept. Polit. Sci., 1997.

La Malène, Christian de. "L'Application du principe de subsidiarité." Report no. 46. Paris: Délégation du Sénat pour l’Union Européenne, 1996/97. http: //cubitus.senat.fr/rap/r96-46/r96-46_mono.html

Moulin, Hervé. "On Strategy-proofness and Single Peakedness." Public Choice 35, no. 4 (1980): 437-55.

Nechyba, Thomas J. "Existence of Equilibrium and Stratification in Local and Hierarchical Tiebout Economies with Property Taxes and Voting." Econ. Theory 10 (August 1997): 277-304. (a)

. "Local Property and State Income Taxes: The Role of Interjurisdictional Competition and Collusion." J.P.E. 105 (April 1997): 351-84. (b)

Peterson, Paul E. The Price of Federalism. Washington: Brookings Inst. (for Twentieth Century Fund), 1995.

Romer, Thomas, and Rosenthal, Howard. "Bureaucrats versus Voters: On the Political Economy of Resource Allocation by Direct Democracy." Q.J.E. 93 (November 1979): 563-87.

Smith, Warrick, and Shin, Ben. "Regulating Infrastructure: Perspectives on Decentralization." In Decentralizing Infrastructure: Advantages and Limitations, edited by Antonio Estache. Washington: World Bank, 1995. 